\title{
Characterization of serum complement immune activity in the prairie rattlesnake (Crotalus viridis)
}

\author{
Sarah J. Baker ${ }^{1 *}$ (D) and Mark E. Merchant ${ }^{2}$
}

\begin{abstract}
Background: Reptile populations face a growing number of threats including global climate change and emerging pathogens. Unfortunately, research investigating the reptile immune system lags behind other taxa groups, hindering our ability to predict or mitigate species' response to threats. Baseline studies are critical for our understanding of reptile immune response and overall health of wild populations.

Results: Treatment of unsensitized sheep red blood cells (SRBCs) with plasma collected from captive prairie rattlesnakes (Crotalus viridis) resulted in volume-dependent hemolysis, with a $\mathrm{CH}_{50}$ of $0.23 \pm 0.01 \mathrm{~mL}$. Kinetic analyses at different temperatures revealed that the hemolysis was relatively rapid, with $50 \%$ of hemolytic activity occurring within $15 \min \left(25^{\circ} \mathrm{C}\right), 18 \mathrm{~min}\left(35^{\circ} \mathrm{C}\right)$, or $23 \mathrm{~min}\left(15^{\circ} \mathrm{C}\right)$, and near maximum hemolysis within 60-90 min at all three temperatures. A comparative thermal profile revealed that complement activity was low at $5^{\circ} \mathrm{C}$, but increased sharply at 10 and $15^{\circ} \mathrm{C}$, and was maximal at $20-30^{\circ} \mathrm{C}$. A steep decline in activity was noted at temperatures $>30^{\circ} \mathrm{C}$. Mild heat treatment of the snake plasma $\left(56^{\circ} \mathrm{C}, 30 \mathrm{~min}\right)$ or treatment with proteases completely abolished the hemolytic activity. In addition, inclusion of 5 mM EDTA inhibited 90\% of the hemolysis, but the activity could be reconstituted with the addition of $15 \mathrm{mM} \mathrm{Ca}^{2+}$ or $\mathrm{Mg}^{2+}$, but not $\mathrm{Ba}^{2+}, \mathrm{Cu}^{2+}$, or $\mathrm{Fe}^{2+}$. Furthermore, the hemolysis was unaffected in the presence of $20 \mathrm{mM}$ methylamine, indicating that the alternative mechanism of complement activation is responsible for the observed activities.
\end{abstract}

Conclusions: Rattlesnakes show a relatively robust innate immune response as measured by hemolysis of SRBCS. However, hemolytic activity is reduced at high temperatures, indicating that rising global temperatures may have immune consequences for snake species, making them more vulnerable to known and emerging pathogens.

Keywords: Snake, Reptile, Innate immunity, Plasma, Vipers

\section{Background}

All animals require immune systems to prevent colonization by potentially pathogenic microorganisms. Host defense mechanisms can be divided into two broad divisions, namely innate and adaptive immunity. Innate immunity is generally nonspecific, does not require previous exposure, and is very rapid in response. In contrast, adaptive immunity requires previous exposure and contains components of "immunological memory," is very specific, but can take several days to develop and launch a coordinated response. Innate immunity is thought to be a

\footnotetext{
* Correspondence: sjbaker2@illinois.edu

${ }^{1}$ Illinois Natural History Survey, 1816 S. Oak Street, Champaign, IL 61820, USA Full list of author information is available at the end of the article
}

more ancient defense, while adaptive immunity involving hypervariability in immunoglobulins appears to have developed in the digestive tract of jawed fishes due to a change in diet and feeding behavior (Flajnik \& Du Pasquier, 2004; Flajnik \& Kasahara, 2001; Matsunaga, 1998; Pancer \& Cooper, 2006).

One important mechanism of innate host defense is the serum complement system. Serum complement is thought to be an important form of immunological defense which developed in deuterostome invertebrates such as sponges, sea urchins, and starfish (Smith, Azumi, \& Nonaka, 1999). Serum complement is an ancient mechanism of innate defense characterized by an activation cascade that culminates in damage to the outer envelope and nonspecific destruction of microbes (Ember \& Hugli, 1997). In addition, 
serum complement exhibits a wide array of other functions, such as opsonization, phagocytosis, chemotactic recruitment of leukocytes, inflammation, and expression of proinflammatory cytokines, that facilitate a multifaceted immune response (Ricklin, Hajishegallis, Yang, \& Lambris, 2010). Serum complement components are also crucial for coordinating some important events in adaptive immune response (Nielsen, Fischer, \& Leslie, 2000).

The serum complement cascade can be activated by three different mechanisms, the classical, alternative, and lectin pathways. The classical mechanism involves the recognition and binding of antigen by antibodies and thus acts as a bridge between innate and adaptive immunity (Porter \& Reid, 1979). The alternative mechanism involves activation via cleavage of an internal thioester in the complement C3 protein (Law \& Dodds, 1997; Pangburn \& Muller-Eberhard, 1983). The lectin pathway is activated when a C-type lectin recognizes and binds to the carbohydrate moiety on the surface of a microbe (Ma et al., 2004; Petersen, Thiel, \& Jensenius, 2001). All three modes of activation converge to a common mechanism and culminate in the formation of a multiprotein complex in the outer membrane of microbes (Dalmasso, Falk, \& Raij, 1989). These complexes cause leakage of cellular contents and lysis in a nonspecific manner.

Compared to other taxa, few studies have been conducted quantifying innate immunity in reptiles, and filling this knowledge gap has been identified as a priority research area (Warr, Smith, \& Chapman, 2003). Ectothermic vertebrates are typically thought to have a more effective innate immunity and less advanced adaptive immune responses (Merchant., 2013; Zimmerman, Vogel, \& Bowden, 2010). Although serum complement has been studied extensively in crocodylians (Merchant et al., 2013; Merchant \& Britton, 2006; Merchant, McFatter, Mead, McAdon, \& Wasilewski, 2010; Merchant, Roche, Sweeney, \& Elsey, 2005; Siroski, Merchant, Parachú Marcó, Pina, \& Ortega, 2010), and less in turtles (Ferronato, Merchant, Marques, \& Verdade, 2009) and Komodo dragons (Merchant, Henry, Falconi, Muscher, \& Bryja, 2012), limited information is known concerning the details of complement activity in snakes. The few early studies that have been conducted show snakes exhibit broad-acting serum complement activities (Kawaguchi, Muramatsu, \& Mitsuhashi, 1978) have an alternative pathway similar to that of mammals (Vogel \& Müller-Eberhard, 1985) and produce a protein similar to that of human complement C3 (da Silva, Calich, Kipnis, \& Alper, 1984). More recently, Sparkman and Palacios (2009) showed that garter snakes (Thamnophis elegans) exhibit strong innate immunity in the form of antibacterial activity of plasma, high serum complement titer, and natural antibody production. Additionally, cottonmouths (Agkistrodon piscivorus) show a strong positive correlation between temperature and complement performance (Graham, Fielamn, \& Mendonça, 2017). Here, we provide a detailed characterization of serum complement activation in the plasma of the prairie rattlesnake (Crotalus viridis).

\section{Methods}

\section{Treatment of animals}

Plasma samples were obtained from 21 (9F:12M) adult long-term captive $C$. viridis. Rattlesnakes were housed in plastic enclosures (Neodesha Plastics, Inc.) on newspaper substrate. Temperature was maintained between 18 and $24{ }^{\circ} \mathrm{C}$ and photoperiod on a 12L:12D cycle. Water was provided ad libitum, and snakes were fed pre-killed mice biweekly. Blood samples were collected from the caudal vein and did not exceed $0.08 \%$ of total snake body mass per sampling event. Whole blood was centrifuged to separate plasma from red blood cells, and collected plasma was pooled and stored at $-20{ }^{\circ} \mathrm{C}$ until use.

\section{Chemicals and biochemicals}

Ten percent $(v / v)$ of sheep red blood cells (SRBCs) was purchased from Rockland Immunochemicals (Rockland, MA, USA). Ethylene diamine tetraacetate was purchased from Sigma-Aldrich (St. Louis, MO, USA).

\section{SRBC hemolysis assay}

The efficiency and mechanism of the serum complement system of innate defense in the plasma of $C$. viridis was investigated by utilizing a SRBC hemolysis assay modified from the method of Mayer (1967). Plasma collected from $C$. viridis $(200 \mu \mathrm{L})$ was incubated with an equal volume of $2 \%$ SRBCs $(v / v)$ for $30 \mathrm{~min}$ at ambient temperature and then centrifuged at $2500 \times g$ for $3 \mathrm{~min}$. The supernatant $(150 \mu \mathrm{L})$ was removed to a 96-well plate, and the optical density was measured at $540 \mathrm{~nm}$ in a BioRad Benchmark Plus microtiter plate reader. To determine the titer-dependent effects of snake plasma on hemolysis, $200 \mu \mathrm{L}$ of different volumes of plasma $(0,200,400,600,800$, and $1000 \mu \mathrm{L})$ diluted in saline was incubated with $200 \mu \mathrm{L}$ of $2 \%$ SRBCs for $30 \mathrm{~min}$ at ambient temperature. The SRBCs were centrifuged, and the optical density of the supernatant was measured as described above. The $\mathrm{CH}_{50}$ for the hemolysis was calculated by the method of Costabile (2010). For the kinetic hemolysis analysis, $7.5 \mathrm{~mL}$ of $25 \%$ snake plasma, diluted in normal saline, was mixed with $7.5 \mathrm{~mL}$ of $2 \%$ SRBCs. Aliquots were removed at various time points $(0,5,10,15,20,30,60$, and $90 \mathrm{~min})$ and centrifuged at $2500 \times g$ for $3 \mathrm{~min}$. The supernatants $(150 \mu \mathrm{L})$ were removed to a 96-well plate, and the optical density was measured at $540 \mathrm{~nm}$ as described 
above. For the thermal profile, equal volumes of $25 \%$ plasma and 2\% SRBCs were equilibrated for 10-15 min from 5 to $40{ }^{\circ} \mathrm{C}$, in $5{ }^{\circ} \mathrm{C}$ increments. The SRBCs were transferred to the plasma, and the resulting mixture was incubated for $30 \mathrm{~min}$ at the respective temperature. The SRBCs were then centrifuged at $2500 \times g$ for $3 \mathrm{~min}$, the resulting supernatant $(150 \mu \mathrm{L})$ was removed to a 96-well plate, and the optical density was measured at $540 \mathrm{~nm}$ as described above.

\section{Statistics and controls}

All experiments were conducted in quadruplicate to enable valid statistical evaluation of the results. The results are presented as the percentage of maximum hemolysis as compared to a positive control (1\% SRBCs) that was completely lysed with detergent and represent the means \pm standard deviation for four independent determinations. The results were subjected to analysis of variance using Scheffe's post hoc comparisons.

\section{Results}

The relationship between $C$. viridis plasma dilution and SRBC hemolysis was biphasic, with a sharp initial increase in activity at low dilutions followed by a slow linear increase at higher dilutions (Fig. 1). Addition of only $6 \mu \mathrm{L}$ of plasma to a $400 \mu \mathrm{L}$ reaction resulted in $31 \%$ of maximal hemolytic activity. Increasing the plasma concentration to $20 \%$ resulted in a sharp increase to $69 \%$ activity. There was a slow, linear increase in activity from 20 to $100 \mu \mathrm{L}$ plasma, with a maximum activity of 93.6\%. The $\mathrm{CH}_{50}$, or the volume required to hemolyze $50 \%$ of $1 \%$ SRBCs in a $1 \mathrm{~mL}$ reaction, was calculated to be $0.23 \pm 0.01 \mathrm{~mL}$.

The kinetic curve for the hemolysis of SRBCs by C. viridis plasma shows the reaction is both time and temperature dependent (Fig. 2). The activity was measured at three different temperatures $\left(15,25\right.$, and $\left.35{ }^{\circ} \mathrm{C}\right)$. After incubation

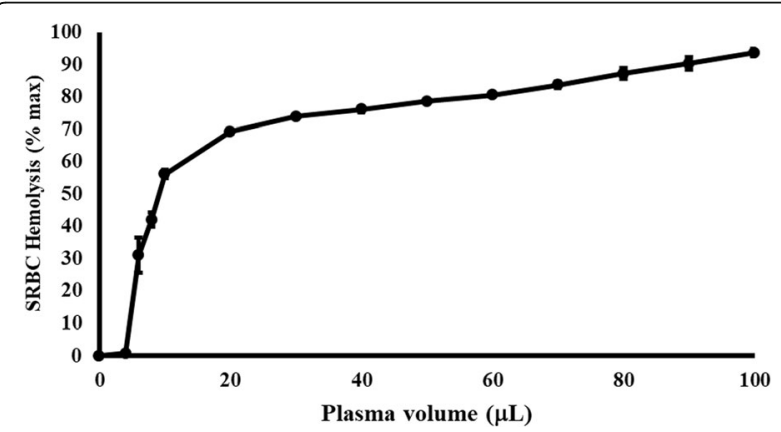

Fig. 1 Concentration-dependent hemolysis of sheep red blood cells (SRBCs) by plasma derived from Crotalus viridis. The samples were centrifuged, and the optical densities of the supernatants were measured at $540 \mathrm{~nm}$ and expressed as the \% maximum as compared to a hemolysis positive control. The results represent the means \pm standard deviations for four independent determinations for $5 \mathrm{~min}$., low levels of activity were detected at 25 and $35{ }^{\circ} \mathrm{C}$, but none was observed at $15{ }^{\circ} \mathrm{C}$. The hemolytic activity was half of the maximum at $15 \mathrm{~min}\left(25^{\circ} \mathrm{C}\right), 18 \mathrm{~min}$ $\left(35^{\circ} \mathrm{C}\right)$, and $23 \mathrm{~min}\left(15^{\circ} \mathrm{C}\right)$. At $60 \mathrm{~min}$, the hemolysis reactions were all at $80-88 \%$ of maximum, with little difference between the three temperatures. Temperature alone has a significant effect on hemolytic activity, with maximal activity at $20-30{ }^{\circ} \mathrm{C}(81.3-82.9 \%$; Fig. 3). Hemolytic activity is lower at extreme ends of the $C$. viridis temperature tolerance range, with significantly less activity occurring at $5{ }^{\circ} \mathrm{C}$ and the lowest observed activity at $40{ }^{\circ} \mathrm{C}$ (Fig. 3).

The hemolytic activity of the plasma from $C$. viridis is heat labile and sensitive to treatment with protease (Table 1). Pretreatment of the plasma at $56{ }^{\circ} \mathrm{C}$ for $30 \mathrm{~min}$ resulted in reduction of SRBC hemolysis by $98.7 \pm 0.7 \%$ (Table 1). Treatment of the plasma with $5 \mathrm{mM}$ EDTA reduced the activity by $90.4 \pm 1.2 \%$ (Table 1 ). The inhibition of $C$. virdis hemolytic activity by EDTA can be restored by the addition of excess $\mathrm{Ca}^{2+}$ and $\mathrm{Mg}^{2+}(10 \mathrm{mM})$, but not $\mathrm{Ba}^{2+}, \mathrm{Fe}^{2+}$, or $\mathrm{Cu}^{2+}$ (Table 2).

\section{Discussion}

Snake populations are declining worldwide (Reading et al., 2010), and some threats to their persistence, including disease, environmental pollution, and global climate change (Gibbons et al., 2000) may interact with immune function. Unfortunately, limited information is available regarding the immune systems of snakes, hindering our ability to understand species or community response to emerging threats. Most work on snake complement proteins has been related to their role as a component of venom, rather than immune function. Therefore, studies such as this quantifying and describing the complement system in a common, wide-ranging snake species are important for increasing our understanding of innate immunity in snakes and provide a baseline to compare with future studies.

Compared to most other reptile and amphibian species, hemolytic activity of $C$. viridis is relatively high. We calculated a $\mathrm{CH}_{50}$ of $0.23 \mathrm{~mL}$ at $25^{\circ} \mathrm{C}$. The $\mathrm{CH}_{50}$ for the American alligator (Alligator mississippiensis) and the estuarine crocodile (Crocodylus porosus) were 0.539 and $0.473 \mathrm{~mL}$, respectively (Merchant \& Britton, 2006). The activities for the toad-headed turtle (Phrynops geoffroanus) and the three-toed amphiuma (Amphiuma tridactylum) were so high that they could not be calculated (Ferronato et al., 2009; Major, Fontenot Jr, Pojman, \& Merchant, 2011). Therefore, the comparatively low $\mathrm{CH}_{50}$ for plasma from $C$. viridis indicates that it has relatively high complement activity. This complement activity is likely responsible for the potent antibacterial activity of C. viridis plasma that we also documented (Baker \& Merchant, 2018). In addition, Kawaguchi et al. (1978) reported that the serum complement activities of five 


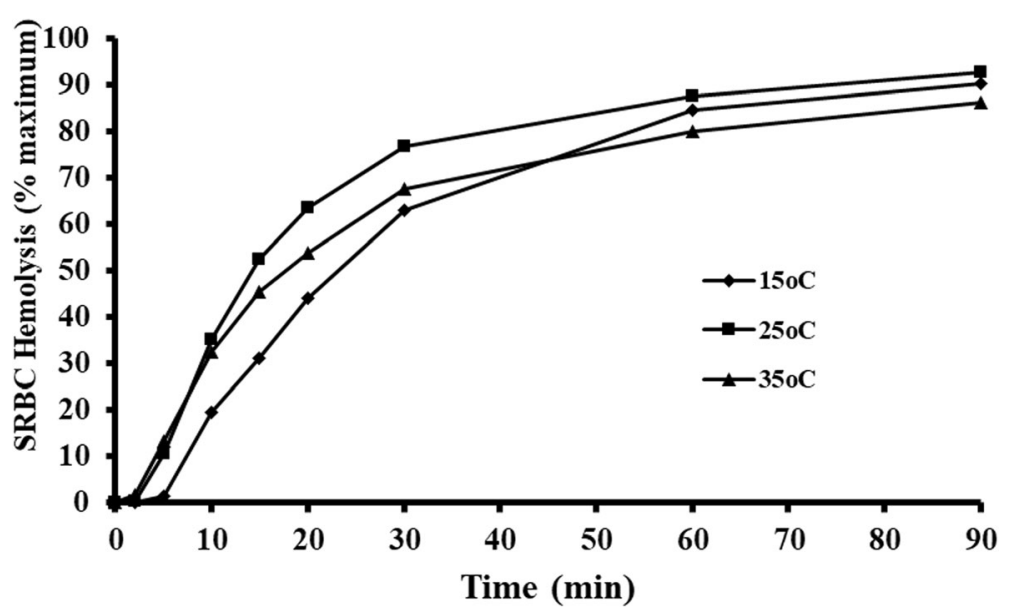

Fig. 2 Kinetic analysis of hemolysis of sheep red blood cells (SRBCs) by Crotalus viridis plasma at different temperatures. SRBCS (1\%, v/v) were incubated with an equal volume of $25 \%$ plasma of C. viridis for different amounts of time and at different temperatures. The samples were centrifuged, and the optical densities of the supernatants were measured at $540 \mathrm{~nm}$ and expressed as the \% maximum as compared to a hemolysis positive control. The results represent the means \pm standard deviations for four independent determinations

colubrid snake species were higher than a bullfrog (Rana catesbiana), a tortoise (Clemmys japonica), and a lizard (Eumeces latiscutatus). However, the evolutionary pressure driving snakes to develop a stronger system of innate immunological defense than other herpetofauna remains unknown.

Experiments with hemolytic inhibitors showed that the hemolytic activity we observed was due to enzymatic activity in the plasma. Components of human serum complement require divalent cations to function correctly (Mayer, Osler, Bier, \& Heidelberger, 1946). The alternative mechanism of serum complement activation is inhibited by EDTA because $\mathrm{Mg}^{2+}$ ions are required for the interaction of C3b with factor B (Gotze, Medicus, Schreiber, \& Muller-Eberhard, 1977). This sensitivity to mild heat treatment and specific dependence on $\mathrm{Mg}^{2+}$ and $\mathrm{Ca}^{2+}$ are characteristic of the alternative mechanism of serum complement activity. It is unlikely that the complement activity from the plasma of $C$. viridis is due to a classical complement pathway that requires presence of natural antibodies. Previous results in our laboratory showed strong antimicrobial activities of plasma from $C$. viridis toward a broad spectrum of bacterial species, which appeared to be mediated by complement (Baker \& Merchant, 2018). It is improbable that $C$. viridis harbors natural antibodies to all of these bacteria, and also to SRBCs, and thus it is likely that the complement activity is mediated by the alternative mechanism. Furthermore, the treatment with $20 \mathrm{mM}$ methylamine or ammonium hydroxide did not affect the plasma-mediated hemolysis (Table 1), as the classical complement mechanism is known to be sensitive to these treatments because amines

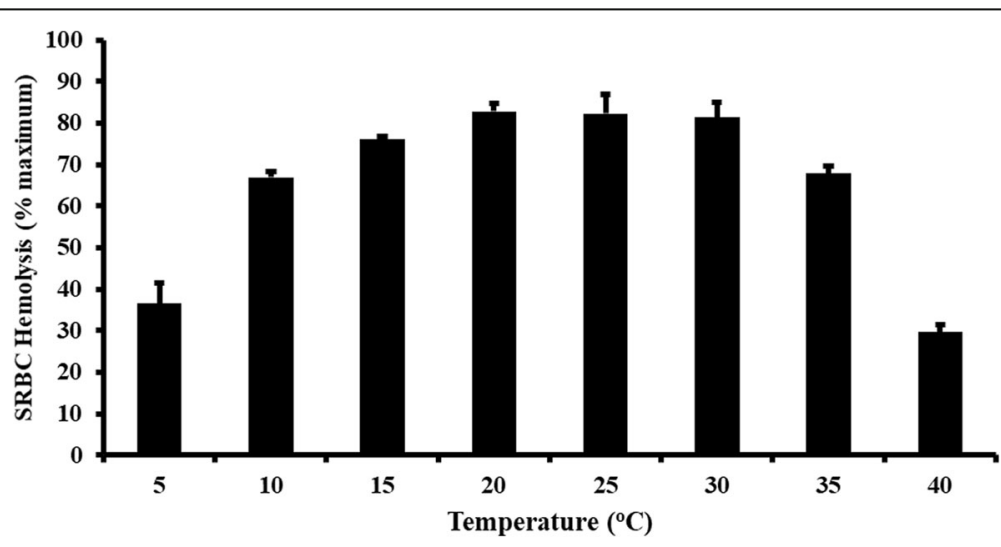

Fig. 3 Temperature-dependent hemolysis of sheep red blood cells (SRBCs) by plasma from Crotalus viridis. SRBCs (1\%, v/v) were incubated with an equal volume of $25 \%$ plasma of $C$. viridis for $1 \mathrm{~h}$ and at different temperatures. The samples were centrifuged, and the optical densities of the supernatants were measured at $540 \mathrm{~nm}$ and expressed as the \% maximum as compared to a hemolysis positive control. The results represent the means \pm standard deviations for four independent determinations 
Table 1 Effects of heat, protease, and specific serum complement inhibitors on the hemolysis of sheep red blood cells (SRBCs) by plasma from Crotalus viridis

\begin{tabular}{ll}
\hline Treatment & $\begin{array}{l}\text { SRBC hemolysis } \\
\text { (\% maximum) }\end{array}$ \\
\hline Snake plasma & $94.7 \pm 1.2$ \\
Snake plasma $\left(56^{\circ} \mathrm{C}, 30 \mathrm{~min}\right)$ & $1.1 \pm 0.3^{*}$ \\
Snake plasma $+20 \mathrm{mM}$ ammonium hydroxide & $91.9 \pm 2.6$ \\
Snake plasma + $20 \mathrm{mM}$ methylamine & $92.1 \pm 1.7$ \\
Snake plasma + $20 \mathrm{mM}$ salicylaldoxime & $6.5 \pm 3.1^{*}$ \\
Snake plasma + $5 \mathrm{mM}$ EDTA & $7.7 \pm 2.4^{*}$
\end{tabular}

Plasma from C. viridis was heat-treated, or treated with protease, EDTA, ammonium hydroxide, methylamine, or salicylaldoxime, and then incubated with $1 \%$ SRBCs for 30 min at room temperature. The samples were then centrifuged at $2000 \times g$, and the optical densities were measured at $540 \mathrm{~nm}$ The results represent the means \pm standard deviations for four independent determinations and expressed as the \% maximum as compared to a hemolysis positive control

*Statistically less than SRBCs treated with plasma alone $(p<0.01)$

inhibit the action of complement C4 (Blom, Villoutreix, \& Dahlback, 2003; Gordon, Whitehead, \& Wormall, 1926; Gorski \& Howard, 1980). Furthermore, the inclusion of $20 \mathrm{mM}$ salicylaldoxime, a compound known to inhibit the alternative mechanism of complement activation (Austen \& Brocklhurst, 1961) resulted in substantial inhibition of hemolytic activity. It is also unlikely that the lectin pathway of complement activation is responsible for the observed hemolytic activities. Although C. viridis express a C-type lectin with specificity toward mannose (Baker and Merchant, unpublished data), this protein serves as pattern recognition for prokaryotic cells, and not eukaryotic erythrocytes as used in this study. The incomplete inhibition of SRBC hemolysis by EDTA suggests the possibility that other mechanisms of immunity might also play a role in hemolysis by the plasma of $C$. viridis. Additional mechanisms such as hemolysis by lytic peptides (Zasloff, 2002)

Table 2 Effects of divalent metal ions on the reconstitution of EDTA-inhibited sheep red blood cell (SRBC) hemolysis

\begin{tabular}{ll}
\hline Treatment & $\begin{array}{l}\text { SRBC hemolysis } \\
\text { (\% maximum) }\end{array}$ \\
\hline Snake plasma & $94.7 \pm 1.2$ \\
Snake plasma + $5 \mathrm{mM}$ EDTA & $9.1 \pm 1.6^{*}$ \\
Snake plasma + $5 \mathrm{mM}$ EDTA $+10 \mathrm{mM} \mathrm{MgCl}_{2}$ & $91.7 \pm 3.6$ \\
Snake plasma + $5 \mathrm{mM}$ EDTA + $10 \mathrm{mM} \mathrm{CaCl}_{2}$ & $93.3 \pm 1.4$ \\
Snake plasma + $5 \mathrm{mM}$ EDTA + $10 \mathrm{mM} \mathrm{BaCl}$ & $3.7 \pm 0.8^{*}$ \\
Snake plasma + $5 \mathrm{mM}$ EDTA $+10 \mathrm{mM} \mathrm{CuCl}_{2}$ & $6.9 \pm 1.4^{*}$ \\
Snake plasma + $5 \mathrm{mM}$ EDTA $+10 \mathrm{mM} \mathrm{FeCl}_{2}$ & $8.7 \pm 1.9^{*}$
\end{tabular}

Plasma from Crotalus viridis was treated EDTA, or EDTA plus and excess of $\mathrm{Ca}^{2}$ ${ }^{+}, \mathrm{Mg}^{2+}, \mathrm{Cu}^{2+}, \mathrm{Ba}^{2+}$, or $\mathrm{Fe}^{2+}$, and then incubated with $1 \% \mathrm{SRBCs}$ for $30 \mathrm{~min}$ at room temperature. The samples were then centrifuged at $2000 \times g$, and the optical densities were measured at $540 \mathrm{~nm}$ and expressed as the \% maximum as compared to a hemolysis positive control. The results represent the means \pm standard deviations for four independent determinations

*Statistically less than SRBCs treated with plasma alone $(p<0.01)$ or other enzyme systems such as phospholipase $\mathrm{A}_{2}$ (Green et al., 1991) or lysozyme (Zimmerman et al., 2010) could also contribute to SRBC hemolysis.

The kinetics of SRBC hemolysis by C. viridis plasma is similar to the kinetics of antibacterial activity of $C$. viridis (Baker \& Merchant, 2018). This strengthens the hypothesis that the antibacterial activities observed were due primarily to serum complement activities. Compared to other species, the kinetics of SRBC disruption by the plasma of $C$. viridis is somewhat slow. We found half of maximal activity was reached in $18 \mathrm{~min}$ at $25^{\circ} \mathrm{C}$; however, half maximal activity was achieved at $25{ }^{\circ} \mathrm{C}$ in only $8 \mathrm{~min}$ and was maximal in $15 \mathrm{~min}$ by plasma from the American alligator (Merchant et al., 2005).

Since rattlesnakes are ectothermic vertebrates that exhibit both daily and seasonal thermal variation, we investigated the effects of a broad range of temperatures on the serum complement system of these animals. These data show that the area of maximal serum complement efficiency fall within the preferred temperature range of C. viridis $\left(28-32{ }^{\circ} \mathrm{C}\right)$ (Gannon \& Secoy, 1985). Similar results have been noted in cottonmouths (A. piscivorus; Graham et al., 2017) and corn snakes (Pantherophis guttatus; Stahlschmidt, French, Ahn, Webb, \& Butler, 2017). It is interesting to note the wide thermal range at which maximum activity was observed. Since $C$. viridis have arguably the largest latitudinal distribution among all species of rattlesnakes, ranging from western Canada to Mexico (Ernst \& Ernst, 2012), it may have been necessary to develop an innate immunity with a wide temperature tolerance. Low activity was observed when the plasma was incubated with SRBCs at $5{ }^{\circ} \mathrm{C}$, as the activity was reduced by $46.3 \%$ (Fig. 3). This might indicate that $C$. viridis are immunologically compromised during the winter months, as their internal body temperatures are known to drop as low $6{ }^{\circ} \mathrm{C}$ in hibernacula (Jacob \& Painter, 1980). Many rattlesnake species participate in communal hibernation, where 10 s to 100 s of snakes hibernate in the same den in very close contact. This might seem to indicate that these animals are subject to spread of contagious disease during times of hibernation. However, as bacterial growth slows substantially at reduced temperatures, a strong host defense might not be necessary under these thermal conditions. Rattlesnakes are generally inactive during winter hibernation months and exhibit metabolic rates that are from 20 to $50 \%$ of the average metabolic rates measured in other snake species during the same period (Beaupre \& Duvall, 1998). They spend most of their time in hibernation with minimal movement, and thus, the probability of contracting infection may be lower. The hemolytic activity of $C$. viridis plasma was also reduced at temperatures above $30{ }^{\circ} \mathrm{C}$, as hemolytic activities fell by $14.9 \%(67.9 \pm 1.7 \%)$ and $52.7 \%(29.6 \pm 1.7 \%)$ at $35{ }^{\circ} \mathrm{C}$ and $40{ }^{\circ} \mathrm{C}$, respectively. 
However, since these temperatures approach or exceed the critical thermal maximum of $38{ }^{\circ} \mathrm{C}$ for $\mathrm{C}$. viridis (Brattstrom, 1965), it is not surprising the activities are reduced at these elevated temperatures.

\section{Conclusions}

Given the growing number of threats faced by reptile species including global climate change and emerging pathogens, studies such as this provide important baseline data on immune function of these taxa. Worldwide declines in snake populations have already been noted (Reading et al., 2010), and an emerging fungal pathogen (snake fungal disease) has shown the potential to cause high rates of mortality in sensitive species (Allender et al., 2016). A more complete understanding of immune function in snakes is therefore critical to their conservation. Future studies should build off this baseline data to develop a more complete understanding of snake immune function, especially as related to pathogen susceptibility and global climate change.

\section{Abbreviations}

C. viridis: Crotalus viridis (prairie rattlesnake); SRBC: Sheep red blood cells

\section{Acknowledgements}

The authors thank Ethan Kessler, Megan Britton, Marta Kelly, Dr. Laura Adamovicz, and Dr. Matt Allender of the University of Illinois Wildlife Epidemiology Laboratory, for helping with the maintenance of animals and collection of blood samples.

\section{Funding}

This work was supported by a College of Science Endowed Professorship (COSEP073) awarded to M. Merchant.

\section{Availability of data and materials}

Please contact the author for data requests.

\section{Authors' contributions}

SJB collected plasma samples, conducted lab work, and contributed to the writing of the manuscript. MEM provided funding, conducted lab work, and contributed to the writing of the manuscript. Both authors read and approved the final manuscript.

\section{Ethics approval}

All work with live animals was conducted under approved University of Illinois Institutional Animal Care and Use Committee protocol \#17013.

\section{Consent for publication}

Not applicable

\section{Competing interests}

The authors declare they have no competing interests.

\section{Publisher's Note}

Springer Nature remains neutral with regard to jurisdictional claims in published maps and institutional affiliations.

\section{Author details}

${ }^{1}$ Illinois Natural History Survey, 1816 S. Oak Street, Champaign, IL 61820, USA. ${ }^{2}$ Department of Chemistry, McNeese State University, Lake Charles, LA 70609, USA.
Received: 18 May 2018 Accepted: 27 September 2018

Published online: 11 October 2018

\section{References}

Allender, M. C., Phillips, C. A., Baker, S. J., Wylie, D. B., Narotsky, A., \& Dreslik, M. J. (2016). Hematology in an Eastern Massasauga (Sistrurus catenatus) population and the emergence of Ophidiomyces in Illinois, USA. Journal of Wildlife Diseases, 52, 258-269.

Austen, K. F., \& Brocklhurst, W. E. (1961). Anaphylaxis in chopped guinea pig liver: III. Effect of carbon monoxide, cyanide, salicylaldoxime, and ionic strength. The Journal of Experimental Medicine, 114, 29-42.

Baker, S. J., \& Merchant, M. (2018). Antibacterial activity of plasma from the prairie rattlesnake (Crotalus viridis). Developmental and Comparative Immunology, 84, 273-278.

Beaupre, S. J., \& Duvall, D. (1998). Integrative biology of rattlesnakes. BioScience, $48,531-538$.

Blom, A. M., Villoutreix, B. O., \& Dahlback, B. (2003). Mutations in the a-chain of C4BP that selectively selectively affect its factor 1 cofactor function. The Journal of Biological Chemistry, 278, 3437-43442.

Brattstrom, B. H. (1965). Body temperatures of reptiles. The American Midland Naturalist, 73, 376-422.

Costabile, M. (2010). Measuring the 50\% haemolytic complement (CH50) activity of serum. Journal of Visualized Experiments, 37, 1923.

da Silva, D., Calich, V. L., Kipnis, T. L., \& Alper, C. A. (1984). Complement in the serum and venom of Brazilian snakes (Crotalidae). Acta Pathologica, Microbiologica, et Immunologica Scandinavica. Supplement, 284, 97-103.

Dalmasso, A. P., Falk, R. J., \& Raij, L. (1989). The pathobiology of the terminal complement complexes. Complement and Inflammation, 6, 36-48.

Ember, J. A., \& Hugli, T. E. (1997). Complement factors and their receptors. Immunopharmacol, 38, 3-15.

Ernst, C. H., \& Ernst, E. M. (2012). Venomous reptiles of the United States, Canada, and Northern Mexico, (vol. 2). Baltimore: Johns Hopkins University Press.

Ferronato, B., Merchant, M., Marques, T. S., \& Verdade, L. M. (2009). Innate immune activity of Phrynops geoffroanus (Testudines, Chelidae). Zoologia, 26(4), 747-752.

Flajnik, M. F., \& Du Pasquier, L. (2004). Evolution of innate and adaptive immunity: Can we draw a line? Trends in Immunology, 25, 640-644.

Flajnik, M. F., \& Kasahara, M. (2001). Comparative genomics of the MHC: Glimpses into the evolution of the adaptive immune system. Immunity, 15, 351-362.

Gannon, V. P. J., \& Secoy, D. M. (1985). Seasonal and daily activity patterns in a Canadian population of the prairie rattlesnake, Crotalus viridus viridis. Canadian Journal of Zoology, 63, 86-91.

Gibbons, J. W., Scott, D. E., Ryan, T. J., Buhlmann, K. A., Tuberville, T. D., Metts, B. S., .. Winne, C. T. (2000). The global decline of reptiles, déjà vu amphibians. Bioscience, 50, 653-666.

Gordon, J., Whitehead, H. R., \& Wormall, A. (1926). The action of ammonia on complement-he fourth component. The Biochemical Journal, 20, 1028-1040.

Gorski, J. P., \& Howard, J. B. (1980). Effect of methylamine on the structure and function of the fourth complement component of human complement, C4. The Journal of Biological Chemistry, 255, 10025-10028.

Gotze, O., Medicus, R. G., Schreiber, R. D., \& Muller-Eberhard, H. J. (1977). Molecular aspects of the properdin system. Monographs in Allergy, 12, 66-77.

Graham, S. P., Fielamn, K. T., \& Mendonça, M. T. (2017). Thermal performance and acclimatization of a component of snake (Agkistrodon piscivorus) innate immunity. The Journal of Experimental Zoology, 327, 351-357.

Green, J. A., Smith, G. M., Buchta, R., Lee, R., Ho, K. Y., Rajkovic, I. A., \& Scott, K. F. (1991). Circulating phospholipase A2 activity associated with sepsis and septic shock is indistinguishable from that associated with rheumatoid arthritis. Inflammation, 15, 355-367.

Jacob, J. J., \& Painter, C. W. (1980). Overwinter thermal ecology of Crotalus viridis in the north-central plains of New Mexico. Copeia, 1980, 799-805.

Kawaguchi, S., Muramatsu, S., \& Mitsuhashi, S. (1978). Natural hemolytic activity of snake serum I. Natural antibody and complement. Developmental and Comparative Immunology, 2, 287-295.

Law, S. K. A., \& Dodds, A. W. (1997). The internal thioester and the covalent binding properties of the complement proteins C3 and C4. Protein Science, 6, 263-4274.

Ma, Y. G., Cho, M. Y., Zhou, M., Park, J. W., Matsushita, M., Fujita, T., \& Lee, B. L. (2004). Human mannose-binding lectin and L-ficolin function as specific pattern recognition proteins in the lectin activation pathway of complement. The Journal of Biological Chemistry, 279, 25307-25312. 
Major, S. R., Fontenot Jr., C. L., Pojman, J. A., \& Merchant, M. (2011). Serum complement activity in the three-toed amphiuma (Amphiuma tridactylum). Comparative Immunology, Microbiology and Infectious Diseases, 34, 115-121.

Matsunaga, T. (1998). Did the first adaptive immunity evolve in the gut of ancient jawed fish? Cytogenetics and Cell Genetics, 80, 138-141.

Mayer, M. M. (1967). Complement and complement fixation. In E. A. Kabat, \& M. M. Mayer (Eds.), Experimental immunochemistry, (2nd ed., pp. 133-240). Springfield: Thomas.

Mayer, M. M., Osler, A. G., Bier, O. G., \& Heidelberger, M. (1946). The activating effect of magnesium and other cations on the hemolytic function of complement. The Journal of Experimental Medicine, 84, 535-548.

Merchant, M., \& Britton, A. (2006). Characterization of serum complement activity of the saltwater (Crocodylus porosus) and freshwater (Crocodylus johnstoni) crocodiles. Comparative Biochemistry and Physiology Part A: Molecular \& Integrative Physiology, 143, 488-493.

Merchant, M. (2013). Chapter 18: From Marshes to medicine: the role of immunological defense in the American alligator. In: Lutterschmidt W., editor. Reptiles in Research: Investigations of Ecology, Physiology, and Behavior from Desert to Sea (pp. 351-365). Hauppauge: Nova Science Publishers, Inc.

Merchant, M., Falconi, R., LaFleur, L., Trahan, C., LeDoux, S., \& Escobedo, A. (2013). Characterization of serum complement activity in three species of crocodilians from southeast Mexico. International Journal of Biochemistry Research and Review, 4, 295-305.

Merchant, M., Henry, D., Falconi, R., Muscher, B., \& Bryja, J. (2012). Antibacterial activity of serum from the Komodo dragon (Varanus komodoensis). Microbiological Research, 4, 16-20.

Merchant, M., McFatter, J., Mead, S., McAdon, C., \& Wasilewski, J. (2010). Identification and characterization of serum complement activity in the American crocodile (Crocodylus acutus). Veterinary Immunology and Immunopathology, 133, 165-169.

Merchant, M., Roche, C., Sweeney, A., \& Elsey, R. (2005). Identification of serum complement activity in the American alligator (Alligator mississippiensis). Comparative Biochemistry and Physiology. B, 141, 281-288.

Nielsen, C. H., Fischer, E. M., \& Leslie, R. G. Q. (2000). The role of complement in the acquired immune response. Immunology, 100, 4-12.

Pancer, Z., \& Cooper, M. D. (2006). The evolution of adaptive immunity. Annual Review of Immunology, 24, 497-518.

Pangburn, M. K., \& Muller-Eberhard, H. J. (1983). Initiation of the alternative complement pathway due to spontaneous hydrolysis of the thioester of C3. Annals of the New York Academy of Sciences, 421, 291-298.

Petersen, S. V., Thiel, S., \& Jensenius, J. C. (2001). The mannan-binding lectin pathway of complement activation: Biology and disease association. Molecular Immunology, 38, 133-149.

Porter, R. R., \& Reid, K. B. M. (1979). Activation of the complement system by antibody-antigen complexes: The classical pathway. Advances in Protein Chemistry, 33, 1-71.

Reading, C., Luiselli, L., Akani, G., Bonnet, X., Amori, G., Ballouard, J., ... Rugiero, L. (2010). Are snake populations in widespread decline? Biology Letters, 6, 777 780.

Ricklin, D., Hajishegallis, G., Yang, K., \& Lambris, J. D. (2010). Complement: A key component for immune surveillance and homeostasis. Nature Immunology, 11, 785-797.

Siroski, P., Merchant, M., Parachú Marcó, V., Pina, C., \& Ortega, H. (2010). Characterization of serum complement activity of the broad snouted caiman (Caiman latirostris, Crocodilia: Alligatoridae). Zoological Studies, 49, 64-70.

Smith, L. C., Azumi, K., \& Nonaka, M. (1999). Complement systems in invertebrates. The ancient alternative and lectin pathways. Immunopharmacol, 42, 107-120.

Sparkman, A. M., \& Palacios, M. G. (2009). A test of life-history theories of immune defence in two ecotypes of the garter snake, Thamnophis elegans. The Journal of Animal Ecology, 78, 1242-1248.

Stahlschmidt, Z. R., French, S. S., Ahn, A., Webb, A., \& Butler, M. W. (2017). A simulated heat wave has diverse effects on immune function and oxidative physiology in the corn snake (Pantherophis guttatus). Physiological and Biochemical Zoology, 90, 434-444.

Vogel, C. W., \& Müller-Eberhard, H. J. (1985). The cobra complement system: I. the alternative pathway of activation. Developmental and Comparative Immunology, 9, 311-325.
Warr, G., Smith, L., \& Chapman, R. (2003). Evolutionary immunobiology: New approaches, new paradigms. Developmental and Comparative Immunology, $27,257-262$.

Zasloff, M. (2002). Antimicrobial activities of multicellular organisms. Nature, 415, 389-395.

Zimmerman, L. M., Vogel, L. A., \& Bowden, R. M. (2010). Commentary understanding the vertebrate immune system: Insights from the reptilian perspective. The Journal of Experimental Biology, 213, 661-671.

\section{Submit your manuscript to a SpringerOpen ${ }^{\odot}$ journal and benefit from:}

- Convenient online submission

- Rigorous peer review

- Open access: articles freely available online

- High visibility within the field

- Retaining the copyright to your article

Submit your next manuscript at $\boldsymbol{\nabla}$ springeropen.com 